\title{
Continuous Measurements of Belowground Nitrous Oxide Concentrations
}

\author{
Gordon Drewitt* \\ Jon S. Warland \\ Department of Land Resource Science \\ Univ. of Guelph \\ Guelph, ON \\ Canada N1G 2W1
}

Nitrous oxide released from soil is a concern since it can act as a potential atmospheric pollutant and it represents a loss of $\mathrm{N}$ from the soil. To better understand the factors controlling $\mathrm{N}_{2} \mathrm{O}$ production and transport, we developed a system to obtain continuous measurements from below the soil surface. The sampling system pulls small volumes of soil gas from buried sample probes through a tunable diode laser trace gas analyzer. The advantage of this system is that it measures concentrations spectroscopically, allowing regular, continuous measurements. This provides it with the distinct advantage of being able to capture shortterm changes in gas concentrations that may be important for nutrient and greenhouse gas budgeting. Furthermore, the system is relatively simple to install and could be integrated into existing field measurements of trace gas flux. Measurements of belowground $\mathrm{N}_{2} \mathrm{O}$ concentrations were obtained during the spring thaw from buried probes in a conventionally tilled field that was planted in soybean [Glycine max (L.) Merr.] the previous summer. Measurements showed that belowground $\mathrm{N}_{2} \mathrm{O}$ concentrations at the 25-cm depth varied between 65 and $85 \mu \mathrm{mol} \mathrm{mol}{ }^{-1}$ before snowmelt. After melting of the snow and the beginning of the soil thawing, $\mathrm{N}_{2} \mathrm{O}$ concentrations decreased to a value generally $<1 \mu \mathrm{mol} \mathrm{mol}{ }^{-1}$. During this period when belowground $\mathrm{N}_{2} \mathrm{O}$ concentrations were near atmospheric values, wind speed influenced concentrations, possibly through a pressure pumping effect.

Abbreviations: TDLTGA, tunable diode laser trace gas analyzer.
$\mathrm{N}$ itrous oxide is produced in soils during the biological processes of nitrification and denitrification. A comprehensive review of these processes can be found in Firestone and Davidson (1989). Current estimates of global $\mathrm{N}_{2} \mathrm{O}$ fluxes suggest that human activities are primarily responsible for the recent increases in measured $\mathrm{N}_{2} \mathrm{O}$ atmospheric concentrations (Ehhalt et al., 2001). In particular, the addition of $\mathrm{N}$ fertilizer to soils has increased the available $\mathrm{N}$ in the soil, which then feeds the various reactions leading to emissions of $\mathrm{N}_{2} \mathrm{O}$. The measured increase in $\mathrm{N}_{2} \mathrm{O}$ concentration in the atmosphere has important implications for stratospheric ozone depletion and climate change (Badr and Probert, 1993). Additionally, since emissions of $\mathrm{N}_{2} \mathrm{O}$ represent a loss of $\mathrm{N}$ from the soil, it is an important consideration for soil nutrient management in agricultural ecosystems (Mosier, 2001). For these reasons, there is a concerted effort to understand the magnitude of the global pools and fluxes of $\mathrm{N}_{2} \mathrm{O}$ and to investigate possible management strategies that can reduce anthropogenic emissions from agricultural ecosystems.

Emissions of $\mathrm{N}_{2} \mathrm{O}$ are controlled by a number of physical, chemical, and biological factors, which affect both its production in the soil and transport through the soil-atmosphere system (Grant and Pattey, 2003). Many of these factors can be very heterogeneous on a scale of meters in typical agricultural settings (Yanai et al., 2003), making it difficult to generalize about the larger scale spatial and temporal behavior of fluxes. Many studies have reported emission "hot spots", which are

Soil Sci. Soc. Am. J. 71:1-7

doi:10.2136/sssaj2005.0410

Received 16 Dec. 2005.

*Corresponding author (gdrewitt@uoguelph.ca).

(c) Soil Science Society of America

677 S. Segoe Rd. Madison WI 53711 USA localized zones that temporarily experience high emissions (Kaiser et al., 1998; Röver et al., 1999). Researchers have also reported a springtime flush of $\mathrm{N}_{2} \mathrm{O}$ from soils, which appears to be related to the thawing of the soil (Nyborg et al., 1997; Koponen and Martikainen, 2004). This flush is probably a combination of increased production due to saturated conditions, increased organic substrate availability from microbial biomass, and sudden changes in soil moisture resulting in changes in the transport and release of $\mathrm{N}_{2} \mathrm{O}$ from soil water. To gain a better understanding of the magnitude of $\mathrm{N}_{2} \mathrm{O}$ emissions and potential best management practices to minimize these emissions, it is critical to develop our suite of tools and techniques to quantify the magnitude of $\mathrm{N}_{2} \mathrm{O}$ produced and stored in soils. Measurements and observations of $\mathrm{N}_{2} \mathrm{O}$ concentrations can, in turn, be used to infer fluxes, which will lead to improved management strategies.

A common method used to investigate $\mathrm{N}_{2} \mathrm{O}$ under field conditions has been the direct measurement of concentrations in the soil, such as those obtained by Colborne et al. (1984) and Kammann et al. (2001). This equipment usually has a buried porous sample tube, which is linked to the soil surface to allow the withdrawal of discrete gas samples. These samples are then analyzed using standard analytical methods such as gas chromatography (e.g., Farell et al., 1993). Unfortunately, the manual sampling required is quite difficult to continue for long periods of time at high temporal resolution. Højberg et al. (1994) used an electrochemical technique to measure $\mathrm{N}_{2} \mathrm{O}$ in soil aggregates, but this method may be difficult to apply to larger spatial areas and could be problematic under field conditions. Other gases that have been measured directly in the soil using advances in sensor technology include $\mathrm{CO}_{2}$ (Tang et al., 2003) and $\mathrm{O}_{2}$ (Wolfbeis, 2004). 
We have developed a method to obtain near-continuous field measurements of $\mathrm{N}_{2} \mathrm{O}$ in the soil using a gas analyzer. These measurements are useful for observing short-term changes in belowground concentrations, allowing better temporal resolution of processes influencing $\mathrm{N}_{2} \mathrm{O}$ production and transport. Since the flux of $\mathrm{N}_{2} \mathrm{O}$ at the surface is ultimately related to the gradient of $\mathrm{N}_{2} \mathrm{O}$ in the soil, these measurements could be valuable in better understanding the processes controlling $\mathrm{N}_{2} \mathrm{O}$ flux into the atmosphere. This system also has the advantage of being able to measure across a relatively large area, thereby providing a degree of spatial integration and eliminating the effects of localized zones of high production. Although the focus of this study was on the measurement of $\mathrm{N}_{2} \mathrm{O}$, the system could easily be adapted to measure other trace gases of interest such as $\mathrm{CH}_{4}$ and potentially even the ${ }^{12} \mathrm{C}$ and ${ }^{13} \mathrm{C}$ isotopes of $\mathrm{CO}_{2}$ (Griffis et al., 2004). Finally, this system is relatively simple and could be integrated into existing micrometeorological flux-gradient measurements of trace gas exchange across agricultural surfaces.

\section{MATERIALS AND METHODS \\ Site Description and General Measurements}

Measurements were obtained at the Elora Research Station located in southern Ontario, Canada $\left(43^{\circ} 30^{\prime} \mathrm{N}, 80^{\circ} 15^{\prime} \mathrm{W}, 340 \mathrm{~m}\right.$ above sea level). The soil is classified as a Woolwich silt loam (29\% sand, $52 \%$ silt, and $19 \%$ clay) with a $\mathrm{pH}$ of $7.7,2.7 \%$ by mass organic $\mathrm{C}$ and $0.24 \%$ by mass organic $\mathrm{N}$. The field used in this study was conventionally tilled, 150 by $100 \mathrm{~m}$, and has been used as one of two control plots in an investigation into no-till agriculture since 1999 (McCoy et al., 2006). Measurements of belowground $\mathrm{N}_{2} \mathrm{O}$ concentration were obtained from $15 \mathrm{Mar}$. to $13 \mathrm{Apr}$. 2005. The crop rotation for this type of farm management system was wheat (Triticum aestivum L.) in 2002, corn (Zea mays L.) in 2003, and soybean in 2004, with all stubble incorporated into the soil during fall plowing. The field is tile drained at a depth of $75 \mathrm{~cm}$ with a spacing of approximately $15 \mathrm{~m}$ between tiles. The terrain slopes $<3 \%$ toward the northeast. At the center of the four plots (two no-till, two control) is a small trailer housing instruments and datalogging equipment.

Soil volumetric water content, $\theta_{v}$, was measured with reflectometers (Model CS615, Campbell Scientific, Logan, UT) inserted at an angle to obtain an integrated measurement in four soil layers (0-10-, 10-40-, 40-70-, and 70-100-cm depths). These reflectometer measurements were calibrated in situ with manual time domain reflectometry measurements throughout the year. Soil temperature was also measured

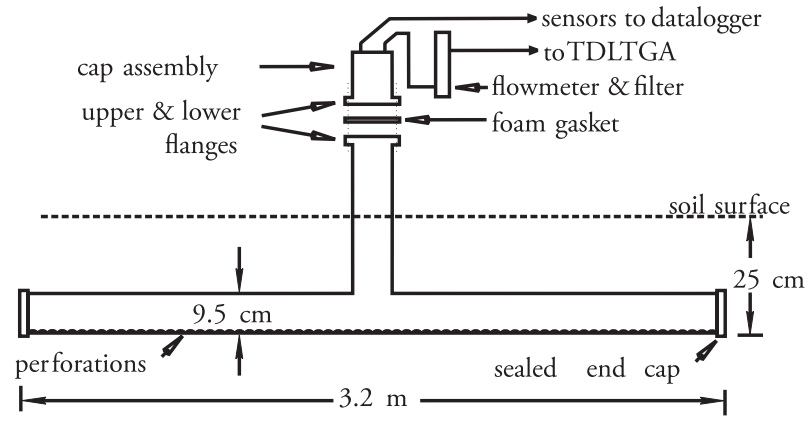

Fig. 1. Schematic of the buried sampling probe used to obtain measurements of belowground $\mathrm{N}_{2} \mathrm{O}$ concentration. Liquid level sensor, thermocouples, and gas sampling tubing extended to the base of the vertical access tube. TDLTGA = tunable diode laser trace gas analyzer. with custom-manufactured direct burial $\mathrm{Cu}$-constantan thermocouples placed at the midpoints of the reflectometer measurement layers. These measurements were obtained at a site approximately $20 \mathrm{~m}$ away from the soil gas sampling probe but in the same field treatment (conventionally tilled). Hourly measurements of precipitation were obtained with a weighing-type rain gauge (Belfort Model 5-780, Belfort Instruments, Baltimore, MD). Air temperature was measured with a Vaisala Model HMP45C-L temperature-humidity sensor (Vaisala Oyj, Helsinki, Finland), and wind velocity measured with a propeller anemometer (Model 05103, R.M. Young Co., Traverse City, MI).

\section{Tunable Diode Laser Trace Gas Analyzer Setup}

The gas analyzer used in this study was a Campbell Scientific tunable diode laser trace gas analyzer (TDLTGA) of which a detailed description is available in Edwards et al. (2003). The advantage of this system is the high sensitivity and the ability to resolve absorption lines of various simple trace gas molecules, including greenhouse gases such as $\mathrm{CO}_{2}, \mathrm{~N}_{2} \mathrm{O}$, and $\mathrm{CH}_{4}$ (Edwards et al., 2003). The laser was tuned to a wavenumber of $2219.5 \mathrm{~cm}^{-1}$, corresponding to a relatively strong $\mathrm{N}_{2} \mathrm{O}$ absorption line with minimal interference from other gases (Rothman et al., 2003). The reference gas used in this study had a concentration of $2498 \mu \mathrm{mol} \mathrm{mol}^{-1}$. The entire system was maintained at a pressure of approximately $1500 \mathrm{~Pa}$ during the measurements, with the soil gas being drawn directly into the $1.53-\mathrm{m}$ sample cell. Since the measurements in this study do not strictly require the $10-\mathrm{Hz}$ sampling capability of the TDLTGA, data were averaged and sampled at $0.2 \mathrm{~Hz}$ via the instrument software settings.

Soil gas was drawn directly from the buried probe (described below) using a single-stage rotary vane vacuum pump (Model RC0021, Busch Inc,, Virginia Beach, VA) into the gas analyzer. A single, two-way alternating current (AC) solenoid valve (Model 8263A35, Ascoelectric Ltd., Brantford, ON) was used to switch flow into the TDLTGA for $20 \mathrm{~min}$ every $2 \mathrm{~h}$. The remaining time, the TDLTGA was sampling room air through a second critical flow orifice and filter assembly. The solenoid valve was controlled by a $21 \mathrm{X}$ datalogger (Campbell Scientific) connected to a custom-built relay board. The sample tubing from the probes to the TDLTGA was 6.4-mm o.d., 4.2-mm i.d. tubing (Synflex 1300, SaintGobain Performance Plastics, Wayne, NJ). This tubing from the buried probe to the TDLTGA was heated with $15 \mathrm{~W} \mathrm{~m}^{-1}$ electrical heating tape and bundled into closed-cell pipe insulation to prevent the relatively warm humid air from below the soil surface condensing and freezing inside the sample tubing.

\section{Soil Gas Sampling Apparatus}

The probe used in this study, shown in Fig. 1, was manufactured from plumbing-grade polyvinyl chloride tubing. The probe had a horizontal length of $3.2 \mathrm{~m}$, a diameter of $9.5 \mathrm{~cm}$ and a $1-\mathrm{m}$-long connected vertical access tube. The bottom of the horizontal tube was perforated with 1.25 -cm-diameter holes, each separated by a distance of approximately $1 \mathrm{~cm}$. The flange of the top cap was attached to the body flange with bolts and was sealed with a 1-cm-thick closed-cell foam circular gasket. The probe was buried so the bottom perforations were, on average, $25 \mathrm{~cm}$ below the soil surface and the upper access tube protruded above the soil surface. Two 6.35-mm (1/4-inch) male National pipe thread (NPT) connectors (Swagelok Corp., Solon, $\mathrm{OH}$ ) were attached to the top cap. One of them was used for the gas sampling while the second was sealed with an epoxy-filled male connector containing wires for a liquid level sensor and thermocouple cables. A 0 to $50 \mathrm{~mL} \mathrm{~min}^{-1}$ flow meter (Model U003(A), Matheson 
Corp., Whitby, ON) was attached to the exterior of the top cap. Downstream of the flow meter was a $0.2-\mu \mathrm{m}, 25-\mathrm{mm}$-diameter Teflon filter (Versapor-200, Gelman Sciences, Ann Arbor, MI) to eliminate contamination of the sample lines or the TDLTGA and to prevent the incursion of liquid water. In laboratory testing, we found that with the sample pump set to the lowest possible pressure $(\sim 1000 \mathrm{~Pa})$, water did not break through the filter. This provided a means of ensuring that the TDLTGA did not draw in water.

An additional water protection feature was a simple, home-made liquid water detector that compared the voltage drop across the second of two resistors in series and a small two-wire probe across the first resistor. When the probe is immersed in conductive liquid water, the short circuit is completed and the measured voltage changes. This device was connected to the $21 \mathrm{X}$ datalogger and provided a relatively crude but reliable method to determine the presence of liquid water in the buried sample tube. The datalogger was programmed to conditionally sample only if water was not present in the sample tube. After installation, the vertical access tube protruding from the soil was heated with a $20-\mathrm{W}$ heater and wrapped in insulation to prevent ice formation from warm humid air from the sampling probe depth.

The sample tube used to draw soil air from the probe to the gas analyzer had an internal radius of $2.1 \mathrm{~mm}$ and a length of approximately $20 \mathrm{~m}$. Laboratory testing showed that the $0.2-\mu \mathrm{m}$ filter was responsible for approximately $75 \%$ of the pressure drop between the intake and the TDLTGA. The low pressure in the sample line provides additional protection against condensation and ice formation. Flow rate at the sample probe was set to approximately $10 \mathrm{~cm}^{3} \mathrm{~min}^{-1}$ at $20^{\circ} \mathrm{C}$ and $101 \mathrm{kPa}$ of pressure. This combination of pressure drop and flow rate produced an average flow velocity inside the sample tube of approximately $0.4 \mathrm{~m} \mathrm{~s}^{-1}$, requiring $50 \mathrm{~s}$ for the sample to travel from the buried probe to the TDLTGA.

For this prototype version of the plumbing system, the 20-min sampling was determined to be sufficient to measure the average concentration inside the buried probe. It was noted that the concentration did not stabilize as quickly as expected during the sampling, which could be attributed to a combination of pressure fluctuations in the TDLTGA, adsorption or desorption of $\mathrm{N}_{2} \mathrm{O}$ inside the plumbing system, or a change in the performance of the sample solenoid between laboratory testing and installation in the field. If the flow resistance of the solenoid was higher than expected, the amount of time for the pressure of the TDLTGA to stabilize would be greater than anticipated and could account for the long period of time for the concentration to stabilize.

The response of the entire flow system was verified by removing the top cap and intake assembly and sampling directly from a tank of $65 \mu \mathrm{mol} \mathrm{mol}-1 \mathrm{~N}_{2} \mathrm{O}$ in air mixture. This was performed at the beginning and end of the month-long measurement period. During both of these calibrations, the system was able to measure the calibration gas concentration to within $1 \mu \mathrm{mol} \mathrm{mol}{ }^{-1}$ in $<10 \mathrm{~min}$. This calibration provided an effective means of verifying the gas measurements before and after the soil gas measurements.

The total volume of the buried sample probe was approximately 20.36 L, not including the vertical access tube (Fig. 1). With a sample flow rate of $10 \mathrm{~cm}^{3} \mathrm{~min}^{-1}$ and a sample extraction duration of $20 \mathrm{~min}$, only $200 \mathrm{~cm}^{3}$, or $<1 \%$ of the probe volume, was withdrawn during any half-hour period. If it can be assumed that $\mathrm{N}_{2} \mathrm{O}$ concentrations in the soil equilibrate in a matter of minutes to hours to the production or consumption of $\mathrm{N}_{2} \mathrm{O}$ in the soil, then withdrawing such a sample volume should not induce driving gradients or mass flow of $\mathrm{N}_{2} \mathrm{O}$-depleted air from the soil surface. Other researchers have demonstrated the utility of soil gas measurement systems that replace withdrawn soil air with an on-line gas mixing apparatus (Gut et al., 1998). Although the system proposed here does not replace the withdrawn gas, the small sample volume relative to the soil probe combined with the relative simplicity of the plumbing makes it a potentially attractive system for belowground concentration measurements.

We recognize that the insertion of a buried probe and withdrawing soil gas may disturb the soil and influence processes in the surrounding soil thereafter. While insertion of a probe in the soil requires extreme care, it is very difficult to determine if there is negligible effect due to the fact that controlled comparison measurements in the field are very difficult in practice. If processes in the soil are assumed to occur mainly in the vertical direction (e.g., water and gas flow), then minimizing the projected area of the probe will reduce the influence on these exchanges; however, increasing the length of the probe will have the desirable effect of sampling from a larger area, thereby providing a degree of spatial averaging. Ultimately the dimensions of a probe such as the one in this study must consider these various factors and the ultimate goals of the measurement campaign.

The probe was installed in October 2004 after the field was harvested and plowed to incorporate the soybean stubble. The probe was installed at the bottom of the plow layer at a depth of approximately $25 \mathrm{~cm}$ below the soil surface. The probe was installed so that it was positioned directly above and parallel to the tile drain nearest the instrument trailer housing the TDLTGA. Placing it in this manner provided an additional degree of safety against drawing water into the system. The plumbing system and gas analyzer were installed in early March 2005 and measurements began on 16 March. When the sample tube was removed in May 2005 before planting, no evidence of water incursion into the vertical sample tube could be seen.

\section{RESULTS AND DISCUSSION Tunable Diode Laser Trace Gas Analyzer Measurements}

An example of the TDLTGA response to one soil gas sampling event is shown in Fig. 2. At 21:40 h, the three-way sampling solenoid switched to pull air from the sample probes. This immediately caused a fluctuation in the concentration, probably due to a pressure difference between the sample and reference cells of the

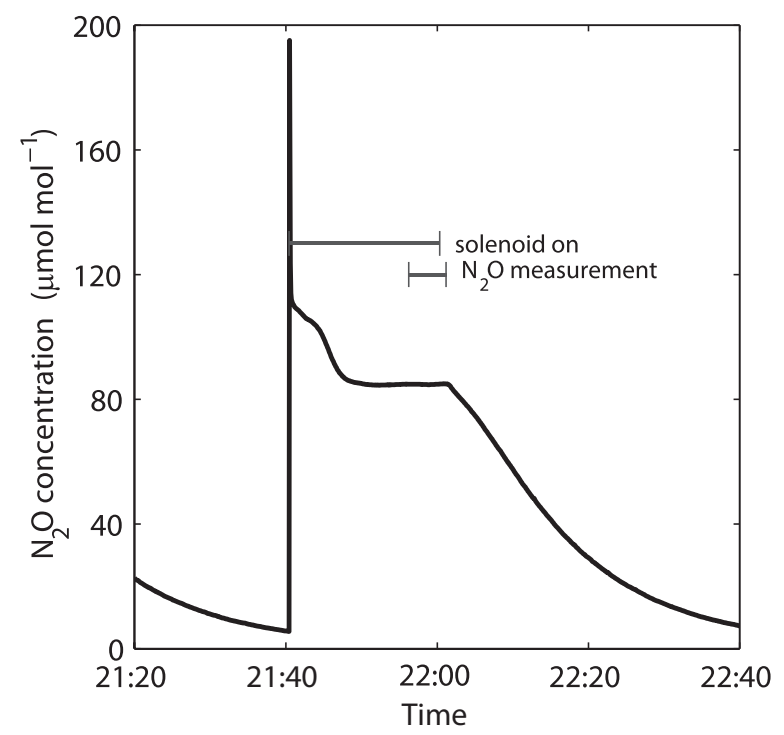

Fig. 2. Time series of $0.2 \mathrm{~Hz} \mathrm{~N}_{2} \mathrm{O}$ concentrations measured by the tunable diode laser trace gas analyzer during soil gas sampling on 27 Mar. 2005. 
gas analyzer. The concentration gradually equilibrated as the previous sample was flushed through the sample tubing between the buried probe and the three-way valve (from 2140 to $2200 \mathrm{~h}$ ) until the concentration stabilized. At this point the 5-s $\mathrm{N}_{2} \mathrm{O}$ concentration measurements were averaged to give a single average concentration measurement. The sampling cycle was repeated every $2 \mathrm{~h}$ to provide 12 measurements of belowground soil $\mathrm{N}_{2} \mathrm{O}$ concentration every $24 \mathrm{~h}$. When the three-way solenoid was switched at $2200 \mathrm{~h}$, room air was drawn through a critical flow orifice and series of filters, which gradually removed $\mathrm{N}_{2} \mathrm{O}$ from the TDLTGA sample tube until the next sampling cycle $2 \mathrm{~h}$ later.

\section{Measurements of Environmental Variables}

Air temperatures, soil temperatures, and soil volumetric water content measured during the period of soil gas sampling

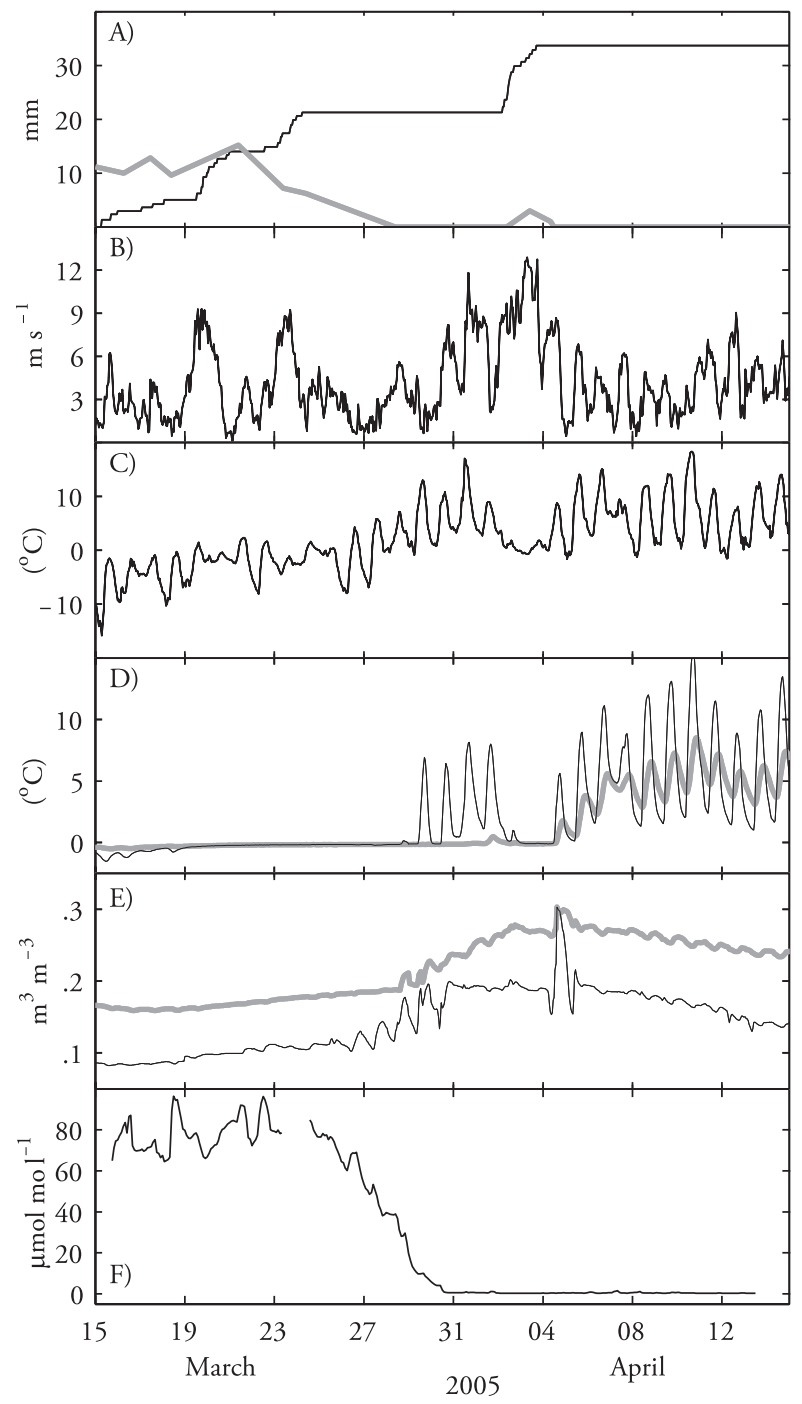

Fig. 3. Time series of measurements during soil gas sampling in March and April 2005: (A) snow depth (thick line) and cumulative precipitation in units of millimeter liquid equivalent (thin line), (B) wind velocity measured at $10 \mathrm{~m}$ above the ground, (C) air temperature measured at $1.5 \mathrm{~m}$ above the ground, (D) soil temperature measured at 5- (thin line) and 25-cm (thick line) depths, (E) soil volumetric water content measured at 5- (thin line) and $25-\mathrm{cm}$ (thick line) depths, and $(\mathrm{F}) \mathrm{N}_{2} \mathrm{O}$ concentrations at the $25-\mathrm{cm}$ depth. are shown in Fig. 3. Also shown are the precipitation (water equivalent), snow depth, and wind velocity measured at 10 $\mathrm{m}$ above the ground, all of which could potentially influence gas transport through soil. During the period shown in Fig. 3 , all precipitation fell as snow except for the final event on 2 Apr. 2005, which was a mixture of snow and rain. During this period, the air temperature showed a relatively strong diurnal trend with a gradual increase over the duration of the period. Soil temperatures showed little diurnal change until approximately 29 March, when the 5 -cm depth became ice free, resulting in large diurnal fluctuations. Subsequently, the 10- to 30$\mathrm{cm}$ layer soil temperature increased, although with the typical lower amplitude and phase lag compared with the temperature measured in the shallower layer.

Soil water content, $\theta_{\mathrm{v}}$, showed a gradual increase during the period around 26 March onward, which is probably due to a gradual decrease in ice content and increase in liquid water content during the thawing process. Additionally, water from the melting snow would probably penetrate the soil, resulting in the observed increase in $\theta_{\mathrm{v}^{*}}$. During the month-long period of these measurements, $\theta_{\mathrm{v}}$ in the 10 - to $40-\mathrm{cm}$ depth layer was higher than the surface measurements but generally followed the same pattern as the surface measurements of $\theta_{\mathrm{v}}$ with a slight temporal lag. These water content measurements were obtained at a distance of $20 \mathrm{~m}$ from the buried gas-sampling probe and were not located near a tile drain. Although these measurements can illustrate the general behavior of $\theta_{v}$ in the soil, the absolute values at the soil gas probe were probably different from these measurements.

\section{Temporal Behavior of Belowground Nitrous Oxide}

Concentrations of $\mathrm{N}_{2} \mathrm{O}$ measured every $2 \mathrm{~h}$ at the 25$\mathrm{cm}$ depth are shown in Fig. 3f. During the period from approximately 15 to 24 March, concentrations measured in the soil averaged $78.1 \mu \mathrm{mol} \mathrm{mol}{ }^{-1}$, with a standard deviation of $7.9 \mu \mathrm{mol} \mathrm{mol}{ }^{-1}$. During this period, the concentrations fluctuated from a minimum of 64.5 to a maximum of $96.4 \mu \mathrm{mol} \mathrm{mol}^{-1}$. Some of these fluctuations occurred during a short time period, such as the increase in the morning of 18 March, when concentration rose by approximately $25 \mathrm{mmol} \mathrm{mol}^{-1}$ in a 2 -h period. Between $0800 \mathrm{~h}, 23 \mathrm{March}$, and $1400 \mathrm{~h}, 24$ March, the data acquisition system failed, resulting in a data gap. Following the system restart, $\mathrm{N}_{2} \mathrm{O}$ concentration began a precipitous decline during the next $6 \mathrm{~d}$ until the concentrations stabilized to just slightly less than $1 \mu \mathrm{mol} \mathrm{mol}{ }^{-1}$.

The presence of snow on the ground will pose an additional resistance for the diffusion of gases from the soil to the atmosphere. During the period when the snow was melting, there was a coincident decrease in $\mathrm{N}_{2} \mathrm{O}$ concentrations (Fig. $3 \mathrm{a}$ and $3 \mathrm{f}$ ). During the period before $30 \mathrm{March}$, there was probably significant melting of ice in the soil, resulting in little temperature change during the ice-water phase change. This physical change from solid to liquid could possibly allow for greater diffusion of trace gases from the soil. Furthermore, it cannot be ruled out that there was a concomitant change in production due to factors influencing microbial $\mathrm{N}_{2} \mathrm{O}$ production, such as the thawing of frozen organic substrate. 


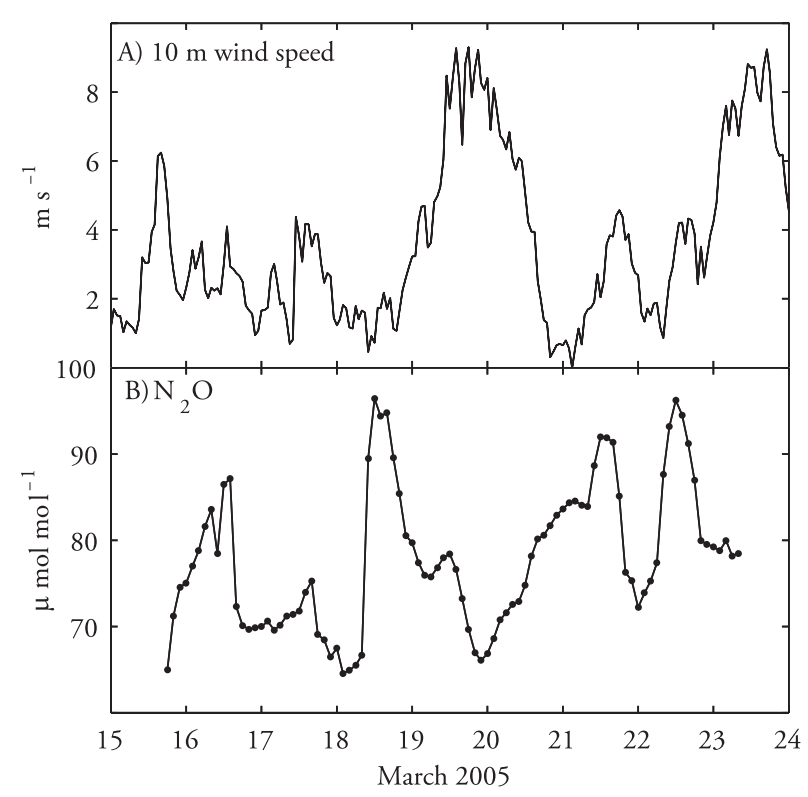

Fig. 4. Time series of (A) wind velocity and (B) $\mathrm{N}_{2} \mathrm{O}$ measurements obtained at the $25-\mathrm{cm}$ soil depth in a conventionally tilled agricultural field between 15 and 24 Mar. 2005.

One factor that does show an influence on $\mathrm{N}_{2} \mathrm{O}$ concentrations in the soil is the wind velocity (Fig. 4 and 5). During the belowground measurements when concentrations were high (15-23 March), there was a general inverse relationship between wind velocity and concentrations. During this period, however, the melting of snow and ice above and within the soil confounds the relationship between soil $\mathrm{N}_{2} \mathrm{O}$ concentrations and the effect of wind. Figure 6 a shows that during this period, the concentrations at high wind speed were slightly lower and less variable than at low wind speeds; however, it is apparent that the relationship is quite noisy due to other factors.

During the period of 31 March to the end of the measurements on 20 April, $\mathrm{N}_{2} \mathrm{O}$ concentrations were relatively low but show a more distinct relationship with wind velocity (Fig. 5 and 6b). Generally, during periods of low wind velocity, concentrations showed more variability, and in some cases were higher by almost a factor of three. Conversely, during periods of high wind velocity, soil $\mathrm{N}_{2} \mathrm{O}$ concentrations fell to typical atmospheric concentrations near $0.3 \mu \mathrm{mol} \mathrm{mol}^{-1}$. We hypothesize that these changes in concentration are similar to those discussed in Massman et al. (1997) and more recently in Takle et al. (2004). The increase in turbulence near the surface results in a pressure pumping effect, which increases the rate of gas movement from the soil pores to the atmosphere. Although a plausible physical mechanism for increasing the rate of gas transport through the soil can help explain sudden changes in concentrations, other factors related to atmospheric turbulence would probably have to be considered as well. The duration and relative frequency of high-wind-speed events could also be important factors in determining concentrations below the soil surface, as would the temporal lag between turbulent conditions and concentration changes.

Relating concentration gradients to surface fluxes could provide insight into the biological and physical processes controlling the production and transport of trace gases in the soil. In this study, only one probe was used to determine the feasibility of this system

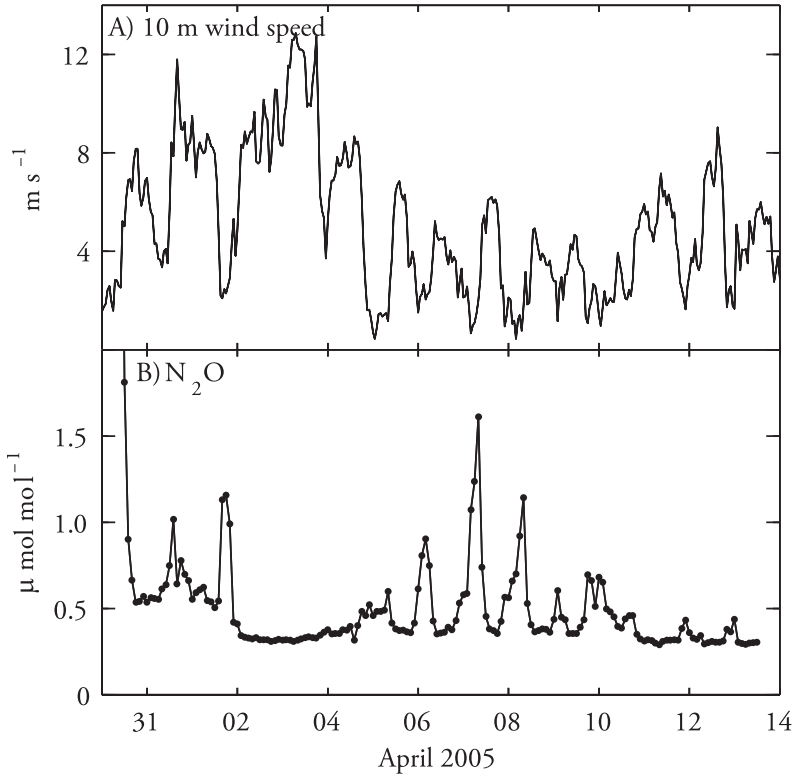

Fig. 5. Time series of (A) wind velocity and (B) $\mathrm{N}_{2} \mathrm{O}$ measurements obtained at the $25-\mathrm{cm}$ soil depth in a conventionally tilled agricultural field between 31 Mar. and 14 Apr. 2005.

for concentration measurements; however, the large concentration change observed during the period of 25 to 31 March (inclusive) represents a change in soil $\mathrm{N}_{2} \mathrm{O}$ storage, which may explain a portion of the surface fluxes. Total porosity of the conventionally tilled fields at the Elora research station is typically $0.5 \mathrm{~m}^{3} \mathrm{~m}^{-3}$. Water content during this period was approximately $0.15 \mathrm{~m}^{3} \mathrm{~m}^{-3}$, resulting in a maximum possible air-filled porosity of $0.35 \mathrm{~m}^{3} \mathrm{~m}^{-3}$. During this period, the soil $\mathrm{N}_{2} \mathrm{O}$ concentration at the $0.25-\mathrm{m}$ depth changed by approximately $80 \mu \mathrm{mol} \mathrm{mol}{ }^{-1}$. Assuming a linear increase in concentration with depth from the surface to the bottom of the plowed layer, a constant soil temperature of $0^{\circ} \mathrm{C}$ and atmospheric pressure

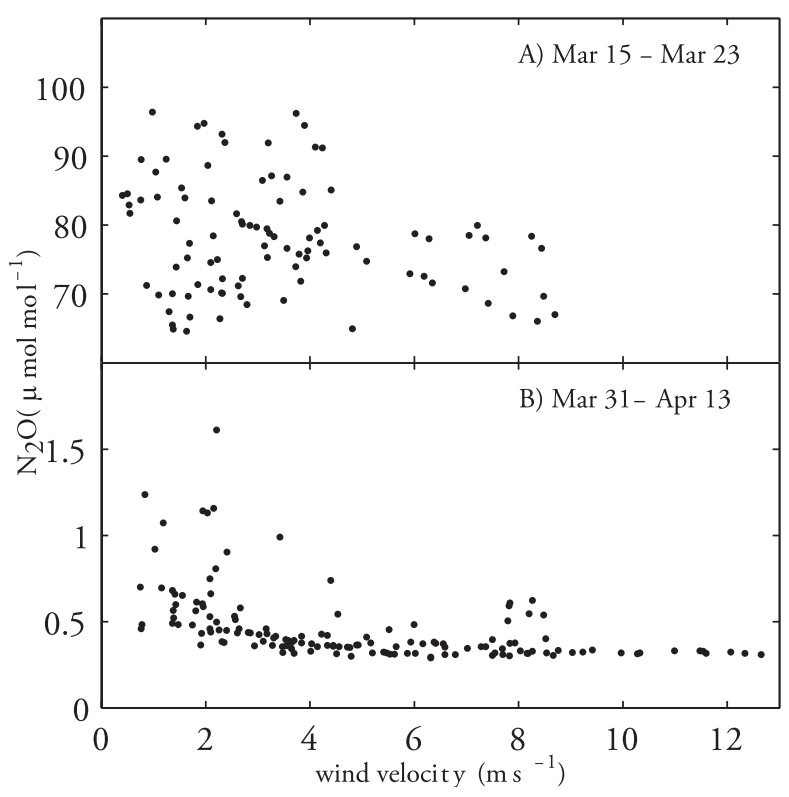

Fig. 6. Relationship of $25-\mathrm{cm}$-depth soil $\mathrm{N}_{2} \mathrm{O}$ concentration and wind speed measured at $10 \mathrm{~m}$ above the surface between (A) 15 and 24 Mar. 2005 and (B) 30 Mar. and 14 Apr. 2005. 
at the site of $98 \mathrm{kPa}$, an average flux of $7 \mathrm{ng} \mathrm{m}^{-2} \mathrm{~s}^{-1}$ of $\mathrm{N}$ during the $7-\mathrm{d}$ period is calculated assuming soil air behaves as an ideal gas. Concurrent micrometeorological measurements during the same period over the conventionally tilled plots show an average flux during this period of $46 \mathrm{ng} \mathrm{m}^{-2} \mathrm{~s}^{-1} \mathrm{~N}$. This result strongly suggests that this single-depth measurement of soil gas storage changes is insufficient to explain the large flux of $\mathrm{N}_{2} \mathrm{O}$ commonly observed during spring thaw conditions (e.g., Maggiotto and Wagner-Riddle, 2000; Teepe et al., 2000).

\section{System Performance and Potential Improvements}

As this was a prototype system, there are various suggested improvements that could easily be implemented in future versions. One possible modification would be to regulate the flow rate from the buried sample probe using a low-flow-rate mass flow controller. Commercial versions of these devices that operate from 1 to $10 \mathrm{~cm}^{3} \mathrm{~min}^{-1}$ are available and would probably be helpful in maintaining a consistent flow rate from the buried probe. While it would be most appropriate to maintain such a flow-control device indoors near the TDLTGA, it may require additional modifications to maintain a low system pressure inside the sample tubing to prevent condensation and ice formation. Related to this suggested improvement would be to use smaller internal diameter sample tubing from the buried probe to the TDLTGA. This would have the advantage of lower pressures, faster flow velocity, and lower volume, which would minimize the time for the TDLTGA to equilibrate to any pressure changes and further reduce the volume of sample required.

A second improvement would be the addition of an automated multiplexing plumbing system to allow the sampling of multiple buried probes. This would allow the measurement of horizontal and vertical gradients of $\mathrm{N}_{2} \mathrm{O}$ in the soil, which would be extremely useful to relate to the surface flux. Computer-controlled relay and solenoid valve systems are available that can be configured for almost any conceivable sampling schedule. The multiple soil probes could be located at various depths and horizontal positions to measure vertical gradients and examine questions of spatial variability of trace gases in soils. Such a system would facilitate direct manipulation studies to address questions such as fertilization and management strategies.

A third modification would be changes to the dimensions of the buried probe. In this study, the probes were fabricated to allow relatively easy installation and burial. It would be feasible, however, to make the probes much longer with a smaller diameter. This would have the desirable effect of reducing any influence of the probe on vertical transport of water or trace gases. Making the probes longer would provide more spatial averaging and allow larger volumes of soil gas to be withdrawn without pulling air from other depths. In this study, the probes were installed approximately $10 \mathrm{~d}$ after plowing in the fall and measurements began in early spring the following year. Although the insertion of any probe into the soil will probably cause some disturbance, careful scheduling of probe insertion can take advantage of agricultural operations to minimize additional disturbance.

\section{CONCLUSIONS}

We developed a relatively simple method to measure trace gas concentrations below ground. The advantages of this method are the ability to obtain nearly continuous measure- ments, thereby removing the need for manual sampling and site visits by skilled personnel. This method provides high temporal resolution measurements, which can capture short-term changes in concentration. This preliminary version of the sampling system could be integrated into the sampling schedule of an existing micrometeorological (flux-gradient) measurement system using a TDLTGA. These measurements could be an important component of trace gas budgeting and monitoring and would complement micrometeorological or chamber studies of ecosystem-atmosphere trace gas exchange. These measurements could ultimately be used to calibrate or validate models of $\mathrm{N}$ cycling in soils. As with many soil measurement procedures, this system requires the insertion of probes, which can cause disturbance of the nearby soil, which makes its utility for measurements in nonagricultural soils questionable. Additionally, the system must be protected against the ingress of water during wet conditions by a membrane barrier or by conditional sampling logic.

Preliminary measurements obtained by this system show that soil $\mathrm{N}_{2} \mathrm{O}$ concentration varied by up to $25 \mu_{\mathrm{mol} \mathrm{mol}}{ }^{-1}$ during a period of hours. Additionally, a large drop in concentration was observed coincident with snow melting and soil warming. This drop in concentration was on the order of $80 \mu \mathrm{mol} \mathrm{mol}^{-1}$ and occurred during a period of approximately $6 \mathrm{~d}$. Analysis shows, however, that this concentration change is insufficient to explain the large flux of $\mathrm{N}_{2} \mathrm{O}$ measured at the site using micrometeorological techniques. During the snow-free period, the concentration of $\mathrm{N}_{2} \mathrm{O}$ in the soil showed a slight inverse relationship with wind velocity, suggesting a pressure-pumping mechanism responsible for trace gas movement from the soil. This system provides a method to obtain $\mathrm{N}_{2} \mathrm{O}$ measurements at a temporal resolution and has the potential to complement standard micrometeorological measurements used to investigate the exchange of other trace gases at the soil surface.

\section{ACKNOWLEDGMENTS}

This research was funded by the Natural Sciences and Engineering Research Council of Canada through a PDF and Discovery Grant. Dr. Claudia Wagner-Riddle is acknowledged for her helpful discussions on operating the TDLTGA and N cycling in soils. Adriana Furon is acknowledged for providing the micrometeorological measurements of $\mathrm{N}_{2} \mathrm{O}$ flux from the field site. Peter von Bertoldi is acknowledged for providing the soil moisture measurements from the field sits.

\section{REFERENCES}

Badr, O., and D. Probert. 1993. Environmental impacts of atmospheric nitrous oxide. Appl. Energy 44:197-231.

Colborne, P., I.W. Harper, and M.M. Iqbal. 1984. Denitrication losses from ${ }^{15} \mathrm{~N}$-labelled calcium nitrate fertilizer in a clay soil in the field. J. Soil Sci. 35:539-547.

Edwards, G.C., G.W. Thurtell, G.E. Kidd, G.M. Dias, and C. WagnerRiddle. 2003. A diode laser based gas monitor suitable for measurement of trace gas exchange using micrometeorological techniques. Agric. For. Meteorol. 115:71-89.

Ehhalt, D., M. Prather, F. Dentener, R. Derwent, E. Dlugokencky, E. Holland, I. Isaksen, J. Katrim, V. Kirchho, P. Matson, P. Midgley, and M. Wang. 2001. Atmospheric chemistry and greenhouse gases. p. 232-288. In J.T. Houghton et al. (ed.) Climate change 2001: Working group 1: The scientific basis. Cambridge Univ. Press, Cambridge, UK.

Farell, R.E., J.A. Elliot, and E. De Jong. 1993. Soil air. p. 179-244. In M.R. Carter (ed.) Soil sampling and methods of analysis. Lewis Publ., Boca Raton, FL.

Firestone, M.K., and E.A. Davidson. 1989. Microbial basis of $\mathrm{NO}$ and $\mathrm{N}_{2} \mathrm{O}$ 
production and consumption in soil. p. 7-21. In M.O. Andreae and D.S. Schimel (ed.) Exchange of trace gases between terrestrial ecosystems and the atmosphere. John Wiley \& Sons, Surrey, UK.

Grant, R.F., and E. Pattey. 2003. Modelling variability in $\mathrm{N}_{2} \mathrm{O}$ emissions from fertilized agricultural fields. Soil Biol. Biochem. 35:225-243.

Griffis, T.J., J.M. Baker, S.D. Sargent, B.D. Tanner, and J. Zhang. 2004. Measuring field-scale isotopic $\mathrm{CO}_{2}$ fluxes with tunable diode laser absorption spectroscopy and micrometeorological techniques. Agric. For. Meteorol. 124:15-29.

Gut, A., A. Blatter, M. Fahrni, B.E. Lehmann, A. Neftel, and T. Staffelbach. 1998. A new membrane tube technique (METT) for continuous gas measurements in soils. Plant Soil 198:79-88.

Højberg, O., N.B. Revsbech, and J.M. Tiedje. 1994. Denitrification in soil aggregates analyzed with microsensors for nitrous oxide and oxygen. Soil Sci. Soc. Am. J. 58:1691-1698.

Kaiser, E.A., K. Kors, M. Kucke, E. Schnug, O. Heinemeyer, and J.C. Munch. 1998. Nitrous oxide release from arable soil: Importance of $\mathrm{N}$-fertilization, crops and temporal variation. Soil Biol. Biochem. 30:1553-1563.

Kammann, C., L. Grunhage, and H.-J. Jaeger. 2001. A new sampling technique to monitor concentrations of $\mathrm{CH}_{4}, \mathrm{~N}_{2} \mathrm{O}$ and $\mathrm{CO}_{2}$ in air at well-defined depths in soils with varied water potential. Eur. J. Soil Sci. 52:297-303.

Koponen, H.T., and P.J. Martikainen. 2004. Soil water content and freezing temperature affect freeze-thaw related $\mathrm{N}_{2} \mathrm{O}$ production in organic soil. Nutr. Cycling Agroecosyst. 69:213-219.

Maggiotto, S.R., and C. Wagner-Riddle. 2000. Winter and spring thaw measurements of $\mathrm{N}_{2} \mathrm{O}, \mathrm{NO}$ and $\mathrm{NO}_{x}$ fluxes using a micrometeorological method. Water Air Soil Pollut.: Focus 1:89-98.

Massman, W.J., R.A. Sommerfeld, K.F. Zeller, T.J. Hehn, and S.G. Rochelle. 1997. A model investigation of turbulence-driven pressure-pumping effects on the rate of diffusion of $\mathrm{CO}_{2}, \mathrm{~N}_{2} \mathrm{O}$ and $\mathrm{CH}_{4}$ through layered snowpacks. J. Geophys. Res. 102:D18851-D18863.
McCoy, A.J., G. Parkin, C. Wagner-Riddle, J. Warland, J. Lauzon, P. von Bertoli, D. Fallow, and S. Jayasundara. 2006. Using automated soil water content measurements to estimate soil water budgets. Can. J. Soil Sci. 86:47-56.

Mosier, A.R. 2001. Exchange of gaseous nitrogen compounds between agricultural systems and the atmosphere. Plant Soil 228:17-27.

Nyborg, N., J.W. Laidlaw, E.E. Solberg, and S.S. Malhi. 1997. Denitrification and nitrous oxide emission from a Black Chernozemic soil during spring thaw in Alberta. Can. J. Soil Sci. 77:153-160.

Rothman, L., A. Barbe, D. C. Benner, L. Brown, C. Camy-Peyret, M. Carleer et al. 2003. The HITRAN molecular spectroscopic database: Edition of 2000 including updates through 2001. J. Quant. Spectrosc. Radiat. Transfer 82:5-44.

Röver, M., O. Heinemeyer, J.C. Munch, and E.-A. Kaiser. 1999. Spatial heterogeneity within the plough layer: High variability of $\mathrm{N}_{2} \mathrm{O}$ emission rates. Soil Biol. Biochem. 31:167-173.

Takle, E.S., W.J. Massman, J.R. Brandle, R.A. Schmidt, X. Zhou, I.V. Litvina, R. Garcia, G. Doyle, and C.W. Rice. 2004. Influence of high-frequency ambient pressure pumping on carbon dioxide flux from soil. Agric. For. Meteorol. 124:193-206.

Tang, J., D.D. Baldocchi, Y. Qi, and L. Xu. 2003. Assessing soil $\mathrm{CO}_{2}$ flux using continuous measurements of $\mathrm{CO}_{2}$ profiles in soils with small solidstate sensors. Agric. For. Meteorol. 118:207-220.

Teepe, R., R. Brumme, and F. Beese. 2000. Nitrous oxide emissions from frozen soils under agricultural, fallow and forest land. Soil Biol. Biochem. 32:1807-1810.

Wolfbeis, O.S. 2004. Fibre-optic chemical sensors and biosensors. Anal. Chem. 76:3269-3284.

Yanai, J., T. Sawamoto, T. Oe, K. Kusa, K. Yamakawa, K. Sakamoto, T. Naganawa, K. Inubushi, R. Hatano, and T. Kosaki. 2003. Spatial variability of nitrous oxide emissions and their soil-related determining factors in an agricultural field. J. Environ. Qual. 32:1965-1977. 